\title{
High rate of molecular alteration in histologically tumour-free bronchial epithelium of NSCLC patients detected by multicolour fluorescence in situ hybridisation
}

\author{
WOLFGANG HILBE ${ }^{1}$, JUTTA AUBERGER ${ }^{1}$, STEPHAN DIRNHOFER $^{5}$, \\ THOMAS SCHMID ${ }^{3}$, MARTIN ERDEL ${ }^{2}$ and HANS-CHRISTOPH DUBA ${ }^{2,4}$
}

\author{
Departments of ${ }^{1}$ Internal Medicine, ${ }^{2}$ Medical Biology and Human Genetics, and ${ }^{3}$ Surgery, \\ Medical University Innsbruck, Innsbruck; ${ }^{4}$ Department of Human Genetics, General Women and \\ Children Hospital, Linz, Austria; ${ }^{5}$ Department of Pathology, University of Basel, Switzerland
}

Received January 18, 2006; Accepted February 7, 2006

\begin{abstract}
Detection of molecular abnormalities could provide an essential tool for the diagnosis of non-small cell lung cancer (NSCLC) and defining patients at risk for early relapse. Fluorescence in situ hybridisation (FISH) targeting 17 gene loci was applied to determine the frequency of molecular alteration in NSCLC probes and adjacent tumourfree bronchial epithelium. FISH was performed on fresh frozen specimens from 76 patients with histologically confirmed NSCLC and 54 specimens of adjacent tumour-free tissue. Routine autopsy lung tissue probes from 7 cancer-free patients served as a control group. Locus-specific (3p14.2, 3p21.2, 3p21.3, 3p25.3, 5p15.2, 7p12, 8q24.12, 9p21, 13q14, and $17 \mathrm{p} 13.1)$ as well as centromere probes $(4,6,7,9,11$ and 16) were used. Molecular alterations using FISH on interphase nuclei were detected in $100 \%$ of NSCLC tumour specimens and $89 \%$ of microscopically tumour-free tissues of NSCLC patients. In histologically 'normal' epithelium, the most frequent alterations were seen with locus-specific probes for $3 p 14.2,3 p .21,3 p 21.3,3 p 25.3$ and $7 p 12$ and centromerespecific probes 11 and 16 (12-93\%). As expected, the majority of genetic alterations seen in 'premalignant' specimens were found in the correlating tumour probes. None of the tested parameters revealed prognostic significance in univariate Cox analysis. FISH analysis, performing multicolour strategies, demonstrated its power in detecting genetic abnormalities in NSCLC specimens and even in tumour-free sections of tumour patients.
\end{abstract}

Correspondence to: Professor Wolfgang Hilbe, Department of Internal Medicine, Medical University Innsbruck, Anichstrasse 35, A-6020 Innsbruck, Austria

E-mail: wolfgang.hilbe@uibk.ac.at

Key words: lung cancer, non-small cell lung cancer, fluorescence in situ hybridisation, multicolour-FISH, screening, field cancerisation

\section{Introduction}

Non-small cell lung cancer (NSCLC) is the leading cause of cancer-related deaths in the Western world. The failure of antismoking campaigns, limitations in cytostatic treatment, as well as the lack of efficient screening tests resulting in delayed diagnoses are the reasons that patient outcome has not improved substantially in recent years. New developments in the field of molecular biology have raised hopes for improving the patient's clinical course. Molecular typing of bronchial epithelium could provide an essential tool for screening programs and, thus, early diagnosis (1-3). After curative surgery, a prognostic assessment identifying patients at risk for early relapse would be of major importance for planning adjuvant treatment modalities. Furthermore, the knowledge of molecular alterations has led to the development of targeted therapies, proving their therapeutic efficacy $(4,5)$.

NSCLC emanates from a multistep carcinogenic process leading to an accumulation of genetic mutations in the bronchial epithelium $(2,3,6-8)$, first generating histologically identifiable 'premalignant' lesions and finally resulting in invasive carcinoma. These genetic alterations simultaneously occur in multiple sites of the respiratory epithelium, a phenomenon called 'field cancerisation' (9-12). Allelic deletions detected as a loss of heterozygosity $(\mathrm{LOH})$ were reported for multiple chromosomal loci, indicating inactivation of several tumour suppressor genes and finally leading to oncogenesis and progression to lung cancer. Recurrent alterations in tumours at numerous chromosomal loci of any chromosome have been seen in NSCLC at a rate between $8 \%$ and $100 \%(3,7,13,14)$.

Several methods (PCR, FISH, immunochemistry, etc.) have been applied to identify $\mathrm{LOH}$ and amplifications of chromosomal regions $(6,14-19)$. Among those, fluorescence in situ hybridisation (FISH) is a simple and sensitive method to detect genetic deletions and amplifications (20-23). Chromosomal abnormalities within interphase nuclei were targeted by using chromosome-specific DNA probes (21). Moreover, FISH offers the possibility of analysing cells directly from tissue sections or cell suspensions without prior 
Table I. Comparison between tumour and premalignant specimens from results of FISH analysis.

\begin{tabular}{|c|c|c|c|c|c|c|}
\hline \multirow[b]{2}{*}{ Parameters } & \multirow[b]{2}{*}{$\begin{array}{l}\text { Cut-offa } \\
\qquad \%)\end{array}$} & \multicolumn{2}{|c|}{ Tumour specimens $(\mathrm{n}=76)$} & \multicolumn{2}{|c|}{ Premalignant specimens $(n=54)$} & \multirow[b]{2}{*}{$\mathrm{p}$-value } \\
\hline & & $\begin{array}{l}\text { No. of positive } \\
\text { cases }(\%)\end{array}$ & Median (range) & $\begin{array}{l}\text { No. of positive } \\
\text { cases }(\%)\end{array}$ & Median (range) & \\
\hline LOH13q14 (RB) & 18.4 & $28(37 \%)$ & $15.8(6.1-40.9)$ & $5(9.3 \%)$ & $13.1(3.5-22.0)$ & 0.000 \\
\hline LOH17p13.1 (p53) & 19.7 & $26(34 \%)$ & $16.9(6.0-48.6)$ & $4(7.5 \%)$ & $10.7(4.2-26.2)$ & 0.000 \\
\hline LOH9p21 (p16) & 17.3 & $13(18 \%)$ & $13.9(6.5-22.0)$ & $3(5.9 \%)$ & $13.0(20.0-6.0)$ & 0.045 \\
\hline LOH 3p14.2 (FHIT) & 5.2 & $63(90 \%)$ & $10.0(2.4-35.3)$ & $35(81 \%)$ & $7.5(1.5-16.7)$ & NS \\
\hline LOH 3p21 & 7.0 & $54(78 \%)$ & $10.5(3.0-46.0)$ & $33(70 \%)$ & $8.0(3.4-13.0)$ & NS \\
\hline LOH3p21.3 & 4.8 & $66(94 \%)$ & $9.5(4.2-56.0)$ & $39(93 \%)$ & $7.4(2.4-15.0)$ & NS \\
\hline LOH 3p25.3 & 5.6 & $62(89 \%)$ & $9.0(1.1-26.8)$ & $39(83 \%)$ & $8.2(3.4-12.5)$ & NS \\
\hline Mon.Chr.4 & 19.7 & $5(7.5 \%)$ & $11.7(1.6-24.9)$ & $1(2.0 \%)$ & $11.4(3.8-21.3)$ & NS \\
\hline Mon.Chr.7 & 25.7 & $2(2.7 \%)$ & $11.6(0.8-25.7)$ & $1(1.9 \%)$ & $11.0(3.0-31.7)$ & NS \\
\hline Mon.Chr.9 & 20.6 & $4(5.5 \%)$ & $13.5(5.0-35.0)$ & $0(0 \%)$ & $13.0(6.5-20.1)$ & 0.091 \\
\hline Mon.Chr.11 & 15.5 & $14(19 \%)$ & $11.5(3.0-25.2)$ & $6(12 \%)$ & $10.6(4.5-29.9)$ & NS \\
\hline Mon.Chr.16 & 16.5 & $9(13 \%)$ & $12.1(1.5-22.5)$ & $13(28 \%)$ & $11.8(4.4-23.5)$ & 0.041 \\
\hline Mon.Chr.17 & 17.5 & $5(6.9 \%)$ & $14.0(7.3-24.5)$ & $3(5.7 \%)$ & $13.5(4.8-19.0)$ & NS \\
\hline Ampl.8q24 (c-myc) & 3.0 & $64(93 \%)$ & $9.1(0.0-51.8)$ & $2(3.7 \%)$ & $3.7(0.0-12.4)$ & 0.000 \\
\hline Ampl.7p12 (EGFR) & 1.7 & $66(96 \%)$ & $8.1(0.0-44.0)$ & $9(17 \%)$ & $2.9(0.0-9.3)$ & 0.000 \\
\hline Ampl.5p15.2 & 8.9 & $29(45 \%)$ & $8.1(0.0-57.4)$ & $0(0 \%)$ & $3.5(0.0-13.4)$ & 0.000 \\
\hline Ampl.CEP Chr.6 & 4.6 & $52(75 \%)$ & $6.4(0.6-40.5)$ & $2(3.7 \%)$ & $4.2(0.9-10.8)$ & 0.000 \\
\hline
\end{tabular}

${ }^{\mathrm{a}}$ Cut-off level was defined by mean $+2 \mathrm{SD}$ of the controls. NS, not signficant.

cell culture. Due to the standardisation of preparation and ease of analysis, this method has gained broad acceptance.

The current study is aimed at defining the frequency of molecular alteration in NSCLC patients. Therefore, 76 tumour specimens were analysed using a panel of centromeric DNA probes for the chromosomes 4, 6, 9, 11, 16 and 17. Probes for specific chromosomal regions, such as $3 \mathrm{p} 14.2,3 \mathrm{p} 21.2,3 \mathrm{p} 21.3$, 3p25.3, 5p15.2, 7p12, 8q24.12, 9p21, 13q14 and 17p13.1, were applied to test either $\mathrm{LOH}$ or amplification. Furthermore, the same markers were examined in 54 microscopically tumour-free specimens of lung cancer patients to define the premalignant molecular profile in NSCLC patients.

\section{Patients and methods}

Patients. In total, 76 tumour and 54 tumour-free specimens from surgically-treated NSCLC patients were analysed. Freshly resected tissue was collected for routine diagnosis. One portion of the sample was fixed in $10 \%$ formalin and routinely processed for paraffin embedding. All surgical tumour specimens were classified histopathologically according to the WHO classification (24). Another portion of surgical samples was used for molecular analysis. The probes were immediately snap-frozen in liquid nitrogen and stored at $-80^{\circ} \mathrm{C}$ until sectioning.

All 76 patients showed histologically quantified tumour cell infiltration. Routine autopsy lung tissue probes from 7 patients who did not suffer from a malignant disease served as a control group for FISH analysis. In the cohort of 76 tumour patients, the histological diagnosis was subdivided as follows: adenocarcinoma (AC), 36 cases; squamous cell carcinoma (SCC), 35 cases; large cell carcinoma, 3 cases; and carcinoids, 2 cases. According to UICC recommendations (25), 49 patients were classified as stage I, 16 patients as stage II, 9 patients as stage III and 2 patients as stage IV. All patients were surgically treated between 1994 and 2001 (pneumectomy in 26 cases, lobectomy in 47 cases and wedge resection in 3 cases). Patients in advanced clinical stages underwent chemotherapy and/or radiotherapy. The median observation time was 31 months (range, 1-127 months), the $50 \%$ survival probability was reached at 65 months, and 30 patients died. At the time of surgery, the median age of patients was 61 years (range, 37-79 years). The male:female ratio was 3.2:1.0 (58/18).

FISH analysis. Frozen lung tissue specimens were cut at $5 \mu \mathrm{m}$ in a cryostat. Before nucleus extraction, cryostat sections were immunohistochemically evaluated to quantify tumour cell infiltration (median, 60\% tumour cells). Malignant cells were mechanically disaggregated and suspended in phosphatebuffered saline solution (PBS), pelleted at $1000 \mathrm{x} \mathrm{g}$, fixed in methanol/acetic acid and stored at $-20^{\circ} \mathrm{C}$. After nucleus extraction (26), fluorescence in situ hybridisation (FISH) was performed as described $(22,27)$. The following probes were used: a) locus-specific probes: LSI ${ }^{\circledR}$ p16 (9p21)/CEP ${ }^{\circledR} 9$ Dual Color Probe; LSI 13 (RB1) 13q14 Probe; LSI p53 (17p13.1) (Vysis Inc.); and probes for 3p14.2, 3p21.2, 3p21.3 and 3p25.3. BAC clones for detecting 3p losses were kindly provided by Drs J.I. Martin-Subero and R. Siebert (Institute of Human Genetics, University Hospital Schleswig-Holstein, Campus Kiel, Germany): 3p14.2 (spans the centromeric and central part of FHIT), RP11-963F9 and RP11-94D19; 3p21.2 
a

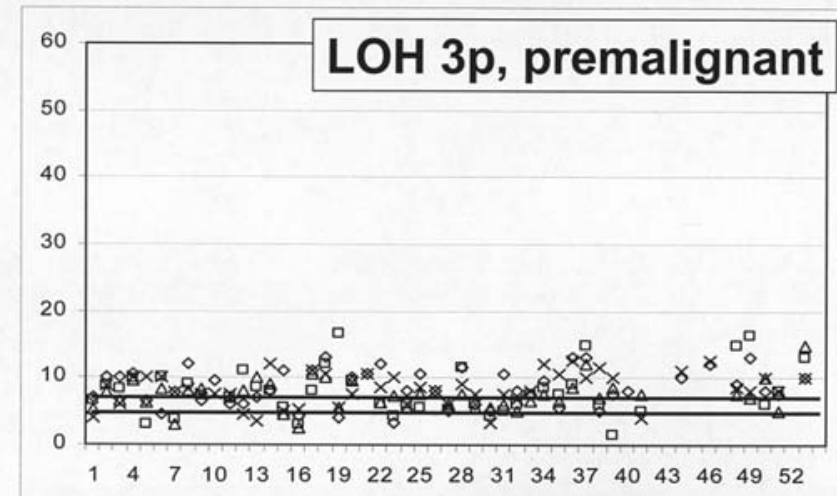

b

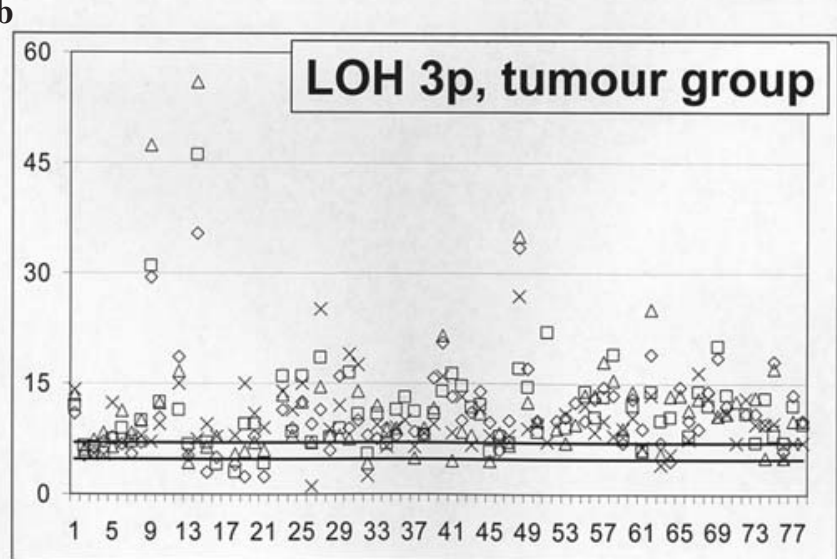

Figure 1. Percentage of nuclei with chromosomal losses of the different $3 p$ regions: $3 \mathrm{p} 14.2$ (rhombus), 3p21.2 x 3p25 (rectangle) and 3p21.3 (triangle). Premalignant (a) compared to tumour-specific alterations (b). X-axis, list of cases; Y-axis, percentage of chromosomal losses.

(spans the complete PCBP4 gene), RP11-314A5; 3p21.3 (spans the complete MLH1 gene), RP11-491D6; and 3p25.3 (telomeric to VHL and spans telomeric part of VHL). The clones were labeled with biotin and digoxigenin, and hybridised to interphase nuclei as previously described $(28,29)$. b) Centromere probes, CEP 4, CEP 7, CEP 11, CEP 16 and CEP 17 (Vysis Inc.); and c) LAVysion ${ }^{\mathrm{TM}}$ multi-colour probe (Vysis Inc.), LSI EGFR (7p12) labeled with SpectrumRed ${ }^{\mathrm{TM}}$, LSI C MYC (8q24.12) probe labeled with SpectrumGold ${ }^{\mathrm{TM}}$, LSI D5S23 and D5S271 (5p15.2) labeled with Spectrum Green $^{\mathrm{TM}}$, and CEP 6 (centromere of chromosome 6, 6p11.1q11) labeled with SpectrumAqua ${ }^{\mathrm{TM}}$.

Hybridisation was carried out overnight at $37^{\circ} \mathrm{C}$. Posthybridisation washing and counterstaining were performed according to the manufacturer's protocol or as previously described. The hybridisation signals on interphases were visualised with single/dual band pass filters for FITC and TRITC, and a multiple band pass filter set for DAPI/Spectrum Green/Spectrum Orange $(28,29)$.

FISH evaluation. Slides were evaluated by three persons (B.E., G.R. and H.C.D.) using a Leitz Aristoplan microscope (Leica, Austria), and 200 interphase cells with clearly separated signals were scored. Copy numbers of the probes were determined for each cell. To establish cut-off levels, FISH was performed in 7 normal human lung tissue specimens, which were taken during the routine autopsy of patients who a

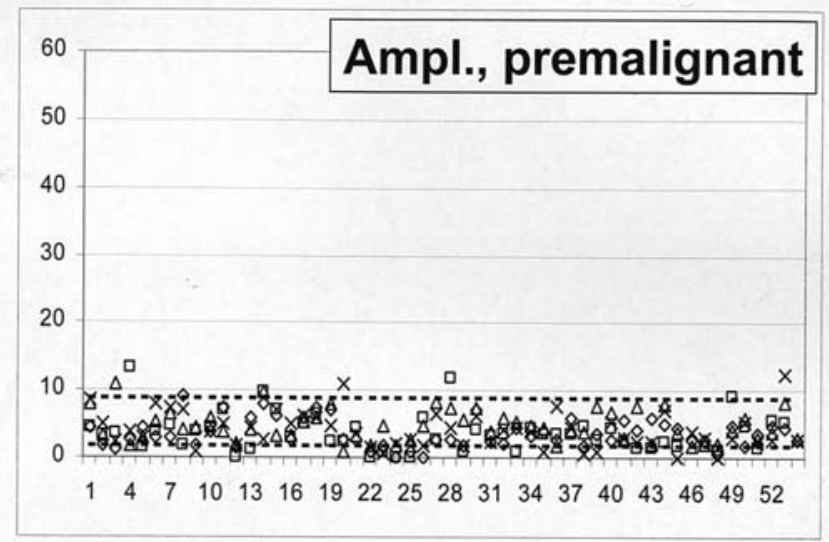

b

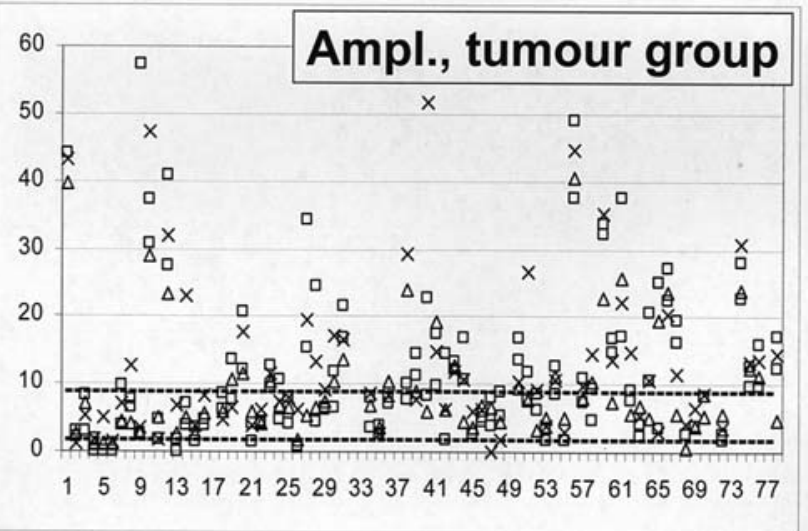

Figure 2. Frequency of amplifications according to the markers $7 \mathrm{p} 12$ (rhombus), 5p12 x 8q24 (rectangle) and C6 (triangle). Premalignant (a) compared to tumour-specific alterations (b). X-axis, list of cases; Y-axis, percentage of chromosomal losses

did not die from malignant disease. All 7 probes were tested, and 200 nuclei were counted in each specimen. For nuclei with one, two, three and more hybridization signals, the mean and standard deviations (SD) according to their percentage were calculated. Based on these results, cut-off levels (mean percentage of nuclei plus 2SD) for the different probes were defined as: LSI p16 (9p21), 17.3\%; CEP 9 dual colour probe, 20.6\%; LSI 13 (RB1) 13q14 probe, 18.4\%; LSI p53 (17p13.1) probe, 19.7\%; 3p14.2, 5.2\%; 3p21.2, 7.0\%; 3p21.3, 4.8\%; 3p25.3, 5.6\%; CEP 4, 19.7\%; CEP 7, 25.7\%; CEP 11, 15.5\%; CEP 16, 16.5\%; CEP 17, 17.5\%; LSI EGFR (7p12), 1.7\%; LSI C-MYC (8q24.12), 3.0\%; LSI D5S23 and D5S271 (5p15.2), 8.9\%; and CEP 6, 4.6\%

Only probes with at least 200 evaluable nuclei and a percentage of aberrations above the predefined cut-off level were scored as 'positive.' Some $7 \%$ of the probes had to be excluded from further analysis since they failed to reach a sufficient number of evaluable nuclei.

Statistical analysis. The Pearson $\chi^{2}$ test was applied to evaluate the differences between the groups. Statistical significance was determined using $95 \%$ confidence intervals. The log-rank test was used to examine the relationship between cancer-specific survival and molecular markers. Cancer-specific survival was defined as the time between surgery and death or last follow-up. All statistical procedures were performed with SPSS statistical software, version 7.5 (SPSS, Inc., Chicago, IL) 
Table II. Patient characteristics.

\begin{tabular}{|c|c|c|}
\hline \multicolumn{3}{|l|}{ Age (years) } \\
\hline Median (range) & $61(37-79)$ & \\
\hline \multicolumn{3}{|l|}{ Gender } \\
\hline \multirow[t]{2}{*}{ Male/female } & $58 / 18$ & Ratio 3.2:1 \\
\hline & $\mathrm{n}$ & $\%$ \\
\hline \multicolumn{3}{|l|}{ Histology } \\
\hline Adenocarcinoma & 36 & $47 \%$ \\
\hline Squamous cell carcinoma & 35 & $46 \%$ \\
\hline Large cell carcinoma & 3 & $4 \%$ \\
\hline Carcinoid tumours & 2 & $3 \%$ \\
\hline \multicolumn{3}{|l|}{ Clinical stage } \\
\hline I & 49 & $64 \%$ \\
\hline II & 16 & $21 \%$ \\
\hline III & 9 & $12 \%$ \\
\hline IV & 2 & $3 \%$ \\
\hline \multicolumn{3}{|l|}{ Surgery } \\
\hline Pneumectomy & 26 & $34 \%$ \\
\hline Lobectomy & 47 & $62 \%$ \\
\hline Follow-up, months (median, range) & 30.5 & $1-127$ \\
\hline Deceased & 30 & $40 \%$ \\
\hline
\end{tabular}

\section{Results}

The analysis was based on three different groups of lung probes: i) Tumour specimens of NSCLC patients ("tumour group'), $n=76$; ii) tumour-free, potentially malignant specimens of NSCLC patients to detect 'premalignant' molecular alterations ('premalignant'), $\mathrm{n}=54$; iii) tumour-free specimens of non-tumour patients ('control') obtained by autopsy to define the cut-off levels (see Materials and methods for details), $n=7$.

Tumour specimens. A median of 8 (range, 2-14) chromosomal alterations per tumour specimen was detected using 17 different molecular targets for FISH (Table I). Frequently, LOH was found at $13 \mathrm{q} 14$ (37\%), 17p13.1 (34\%) and 9p21 $(18 \%)$. Monosomies of the centromeric probes CEP 4, 7, and 17 were rarely diagnosed $(<10 \%)$. Monosomies of CEP 11 and CEP 16 were seen in $19 \%$ and $13 \%$ of cases, respectively. Concerning the four different regions tested on chromosome 3 (3p14.2, 3p21.2, 3p21.3 and 3p25.3), LOH was found in between $63 \%$ and $89 \%$ of cases (Fig. 1a and b). Amplifications of the regions, $8 \mathrm{q} 24,7 \mathrm{p} 12,5 \mathrm{p} 15.2$ and CEP 6, were diagnosed in $93 \%, 96 \%, 45 \%$ and $75 \%$, respectively, as measured by the multicolour probe (Fig. 2a and b).

In adenocarcinoma (AC), CEP 4 monosomies were never seen, in contrast to $13 \%$ of SCC and $33 \%$ of LCC ( $p=0.031)$ (Table II). An interesting though not significant detail was seen for CEP 7, which was increased in only one case with LCC and in another case with a carcinoid, but never in AC or squamous cell carcinoma (SCC). All other FISH markers were distributed equally within the histological subtypes. Due to their small number, the statistically significant differences seen in two carcinoid cases did not constitute clinical relevance (Table II).

No correlations were found between gender, nodal status and the different molecular parameters. Concerning the clinical stages, the following specific features must be noted: two CEP 7-positive cases were exclusively found in clinical stage II ( $\mathrm{p}=0.004)$; and 3p14.2-positive cases were predominantly seen in stage I $(44 / 63,70 \%)(\mathrm{p}=0.029)$ and less frequently in stage II $(4 / 7,57 \%)$. Stage III/IV correlated with increased 3p21.2 LOH $(\mathrm{p}=0.019)(9 / 11,82 \%$ vs. $45 / 58,78 \%)$. Tumour grading correlated with $3 \mathrm{p} 14.2(\mathrm{p}=0.024)$, showing $67 \%$ positive cases in grade I, $91 \%$ in grade II and $96 \%$ in grade III tumours.

Microscopically tumour-free specimens ('premalignant') and comparison with the tumour group. In the 54 tumour-free specimens, the frequency of FISH alterations was lower when compared with the tumour probes. However, even $89 \%$ of patients revealed at least one alteration. The median number of increased parameters was four (range, 0-7) (Table I). Only six cases remained negative, and none of the four $3 p$ markers were evaluable in five of them due to a technical reason. If those cases had been excluded from further analyses, 98\% of the cases would have revealed molecular alterations. When compared with the tumour probes, slightly decreased percentages of FISH markers were found for the $3 p$ regions and CEP 4, 7, 9, 11 and 17. These differences were not statistically significant. Only CEP 16 showed a slightly higher percentage of positive cases $(13 / 47$ vs. 9/71; $p=0.034)$. Compared with the tumour probes, major differences were seen using the multicolor probe; the rate of amplification $(0-17 \%)$ was significantly lower, and $13 q 14(9 \%)$ and 17 p13.1 $(8 \%)$ were diagnosed less frequently when compared with the tumours.

Detailed analysis of pairs $(n=46)$. The majority of genetic alterations $(134 / 165,81 \%)$ seen in tumour-free specimens were also found in the correlating tumour probes. In 19/46 'premalignant' specimens, however, 31 (19\%) additional genetic lesions were detected, which were not altered in the correlating tumour probe. Most frequently, CEP $16(n=8)$, CEP $11(n=6), 13 q 14(n=4), 9 p 21(n=3)$ and CEP $17(n=3)$ were detected. CEP4, 6 and 7, and 17p13.1, 3p21.3 and 3 p25.3 were rarely seen $(n=1-2)$.

Survival analysis. None of the tested molecular parameters revealed statistical significance in univariate survival analysis (log-rank test). Even different combinations of independent parameters (e.g. 3p21.2, 13q14, 8q24.12, CEP 4 and 9p21) revealed no prognostic significance in the log-rank analysis. In 'premalignant' tissue, molecular alterations failed to prove prognostic relevance.

\section{Discussion}

The early detection of molecular alterations for lung cancer screening (1) and the identification of patients with more aggressive tumour types and reduced survival probability are 
challenging. Therefore, the present study analysed the rate of genetic alterations in tumour and tumour-free 'premalignant' lung specimens of NSCLC patients, applying FISH that targeted 17 different gene loci.

We demonstrated that: i) lung cancer specimens reveal a broad spectrum of different genetic abnormalities according to the heterogeneity of the disease; ii) the molecular alterations we tested failed to prove prognostic relevance; iii) genetic alterations in 'microscopically normal' 'premalignant' bronchial epithelium are seen at a very high frequency, and their detection is feasible using multiple FISH probes. Consequently, FISH proved its potential as a tool for lung cancer screening.

Molecular alterations using FISH on interphase nuclei were detected in $100 \%$ of NSCLC tumour specimens and $89 \%$ of microscopically tumour-free tissues from the same patients. As expected, the majority of genetic alterations seen in 'premalignant' specimens were found in the correlating tumour probes.

$\mathrm{LOH}$ on the different regions of the short arm of chromosome 3 (3p14.2, 3p21.2, 3p21.3 and 3p25.3.) belonged to the most frequent alterations (70-93\%). The frequency was similar in 'premalignant' and tumour tissues. These results are concordant with previous reports finding that $3 p$ deletions are often seen $(30,31)$ and occur at an early stage in the pathogenesis of lung carcinoma (10). In detail, LOH of 3 p21.2, 3p22-24 and 3p25 is known to occur early, whereas LOH of 3 p12, 3p14.2 and 3p14-21 is mainly present in advanced lesions $(6,10,32)$. However, this sequence has been observed divergently by others $(33,34)$. For example, the rate of $3 \mathrm{p} 21 \mathrm{LOH}$ is reported to increase during progression from histologically normal to hyperplastic and dysplastic lesions to invasive lung cancer $(0 \%, 31 \%, 83 \%$ and $100 \%)$, applying a microdissection/PCR method (34). One of the most interesting genes is located at 3 p14.2, the FHIT (fragile histidine triad) gene, which is a candidate suppressor gene in lung cancer $(16,35)$. $\mathrm{LOH}$ of that locus was found in $81 \%$ of tumour-free specimens. Similarly, previous data generated with PCR analysis showed $75 \%$ positivity in smokers (7). This is contradictory to Fong et al who stated that $3 \mathrm{p} 14.2 \mathrm{LOH}$ occurred at the stage of carcinoma in situ (CIS) and not before (36). In conclusion, the high rate of alteration for the $3 \mathrm{p}$ loci in 'premalignant' lesions make this a valuable target in a possible screening test.

LOH of 17p13.1 marks the gene locus of the tumour suppressor gene, p53 (37). p53 mutations are critical for lung cancer development and may indicate a biologically more aggressive disease $(38,39)$. As expected, alterations of p53 are frequently seen in tumour probes. Previous data reported deletions of p53 in $25-73 \%$ of tissues (40) and point mutations in $21-51 \%$ of cases (summarized in ref. 41 ), which agrees with the present data detecting a $17 \mathrm{p} 13.1 \mathrm{LOH}$ rate of $34 \%$. Concerning the 'premalignant' samples, $8 \%$ revealed LOH at this locus. Similarly, Jassem and colleagues found genetic mutations of p53 in $9 \%$ of apparently tumour-free surgical margins (42). An even higher percentage of $18 \%$ was found by Mao et al using a PCR methodology in chronic smokers (6). Therefore, the detection of LOH 17p13.1 in normal bronchial epithelia confirms its critical role towards malignancy.
The chromosomal region, $13 \mathrm{q} 14.11$, encodes the retinoblastoma gene (RB), which is a key element for cell cycle regulation $(43,44)$. The loss of $\mathrm{RB}$ function by deletions or mutations occurs in approximately $15-30 \%$ of NSCLC (45-48). In the present study, $9 \%$ of the 'premalignant' specimens and $37 \%$ of the tumours showed an aberration of RB. LOH of $13 q 14.11$ increased throughout the malignant process, and a significant correlation was found between LOH 13q14.11 and LOH 17p13.1. All of these results confirm the crucial role of $\mathrm{RB}$ within the carcinogenic process.

The 9p21 locus (CDKN2 or MST1 or p16INK4) harbours another putative TSG, which encodes an inhibitor of the cyclin-dependent kinase 4 (p16) (49,50). 9p deletions occur in some cases of hyperplasia $(7-9,15)$ and alterations were also diagnosed in smokers $(6,15)$. In tumours, allelic loss is detected in between $16 \%$ and $100 \%$ of cases $(2,14,34,51,52)$. Using a PCR protocol, Sanz-Ortega and colleagues found $\mathrm{LOH}$ of 9p21 in tumour tissue in $48 \%$ and in normal bronchial cells adjacent to NSCLC tissue in $27 \%$ (53). In the present study, LOH of $9 \mathrm{p}$ was seen in $18 \%$ of tumour specimens and only $6 \%$ of tumour-free probes of cancer patients. The use of different techniques (PCR vs. FISH) and a low number of patients leads to divergent results and, therefore, a comparison seems problematic.

The present study also investigated a number of centromeric probes (CEP 4, 7, 9, 11, 16 and 17). With the exception of CEP 16, LOH was found more frequently in tumours; however, the differences were not statistically significant. The lower rate of LOH CEP 16 in cancer specimens was unexpected. In lung cancer, chromosome 16 is affected in different ways. It harbours the MRP1 (multidrug resistance associated protein) gene, which is reported to be overexpressed in NSCLC (54). Moreover, 16p is frequently altered in AC (55), and the loss of chromosome bands 16q24.1-q24.2 (H-cadherin-CDH13) has been reported in lung cancer (56). Alteration of a centromeric region indeed proves chromosomal alteration, but cannot point to a specific gene defect.

$\mathrm{LOH}$ of the centromeric region of chromosome 11 was found in $12 \%$ of 'premalignant' tissue and $19 \%$ of tumours. Chromosome 11 harbours multiple TSGs such as TSLC1 and PPP2R1B $(57,58)$ and inhibitors of apoptosis (cIAP1 and cIAP2) (59). The high rate of alterations seen in microscopically tumour-free tissue suggests that some of these alterations could be an early event in the lung carcinogenic process.

A specially designed FISH probe panel, LAVysion, was introduced to facilitate the detection of frequently altered regions in NSCLC (60). Using four colours enables the simultaneous analysis of probes for centromere 6, 5p15.2, 7p12 (EGFR) and 8q24 (c-myc) in a time-saving procedure. In our large series, a high frequency of amplifications was seen in lung cancer probes (45-96\%) with $100 \%$ of the cases showing at least one alteration. However, with the exception of $7 \mathrm{p} 12$ amplification $(17 \%)$, the rate of alteration was very low in 'premalignant' tissue (0-4\%). Consequently, the screening of molecular alterations in histologically normal epithelium using CEP 6, 5p15.2, and 8q24 seems limited. The higher rate of $7 \mathrm{p} 12$ amplification fits with the known overexpression of EGFR in metaplastic bronchial epithelium $(61,62)$. Similarly, Romeo et al found amplification of centromere 6 
in $19 \%, 5 \mathrm{p} 15.2$ in $13 \%, 7 \mathrm{p} 12$ in $15 \%$ and $8 \mathrm{q} 24$ in $22 \%$ in normal epithelium of 'high risk' patients $(n=11)(60)$. The higher rates seen in that study can be explained by a smaller number of patients and a divergent definition of cut-off levels. Concerning tumour tissue, they also found an absolute sensitivity of $100 \%$ (20/20, with at least one aneusomy). Analysing BALs from lung cancer patients using a slightly different mixture of FISH probes including 5p15, 8q24, 7p12 and the centromeric region of chromosome 1, Sokolova and co-workers reached a sensitivity and specificity of $82 \%$ each. FISH detected 15 of 18 specimens that were falsely negative by cytology (63).

Comparing 'premalignant' and tumour specimens, significant differences were seen for $\mathrm{LOH} 13 \mathrm{q} 14,17 \mathrm{p} 13.1$, 9p21 and CEP 16, and amplification of 8q24, 7p12, 5p15.2 and CEP 6 (Table I). Therefore, these alterations seem to be altered in late stages of the carcinogenic process. Similarly, Fong et al reviewed a model of sequential $\mathrm{LOH}$ at chromosome regions $3 \mathrm{p}, 9 \mathrm{p}, 8 \mathrm{p}, 17 \mathrm{p}$ and $5 \mathrm{q}$ and ras mutations, and stated that some molecular heterogeneity in overt cancers exists (33). However, $0-9.3 \%$ of the tumour-free probes revealed hits at the same loci, indicating a higher malignant potential of these cases.

Similar frequencies between tumour and tumour-free probes were seen for the following loci: $\mathrm{LOH}$ of all four $3 \mathrm{p}$ loci, and CEP 4, 7, 11 and 17. This is indicative of lesions occurring at an earlier stage of carcinogenesis and a genetically altered but not yet malignant bronchial epithelium. From a diagnostic point of view, these hits are of minor value when differentiating between 'premalignant' lesions and invasive carcinoma, but could possibly be valuable for screening. Remarkably, 19\% of molecular lesions seen in premalignant tissue were not detected in the correlating tumour probe. Most frequently, $\mathrm{LOH}$ of CEP 16, CEP 11, 13q14, 9p21 and CEP 17 disappeared, which was more surprising since even 'late stage' hits such as $13 q 14$ were involved. However, the question of the absolute rate of revertible lesions is unanswerable with the current data. As reported in the literature, some alterations may be reversible if carcinogen exposure ceases $(61,64,65)$.

All tested molecular alterations failed to prove prognostic relevance in the tumour cohort and 'premalignant' group. Even combinations of independent variables did not appear to influence survival. Must we conclude that the tested genetic lesions are of minor biological importance? Not at all. We are confronted with genetically profound heterogeneous tumours in which multiple defects can occur at every stage of the carcinogenic process. However, we may conclude that testing only a few markers is insufficient. Certainly, a larger number of patients should be analysed to corroborate or disprove this assumption. Concerning the prognostic value of molecular alterations in the literature, conflicting results have been reported (66-68).

A number of molecular approaches have been tried in an attempt to increase the sensitivity for screening and detection of NSCLC. These comprise microsatellite analysis, mutation analysis, or antigen-based methods (69-74). In our opinion, FISH analysis of normal bronchial epithelia renders an exceptional role, since this technique can easily be introduced to various laboratories and could therefore facilitate international cooperation.
These results affirm that FISH using multiple probes could achieve a high sensitivity for the detection of genetic changes in 'premalignant' and cancer tissues. In this study, 17 molecular markers were analysed, but testing five to six loci would have been sufficient to identify a maximum of altered cases in tumour and tumour-free probes.

With the supplementation of other molecular screening methods, sensitivity might be further augmented. In the future, genetic characterisation of 'normal' bronchial epithelium will be feasible, allowing a better estimation of the individual risk for developing NSCLC. 'Genetically high risk' patients should be surveyed under strictly monitored controls including lowdose CT (75).

\section{Acknowledgements}

The study was supported by the Association for Cancer Research, Innsbruck (Verein für Tumorforschung, Innsbruck). We thank F. Oberwasserlechner, B. Egerth and G. Rammesmayer for their excellent technical assistance. BAC clones for detecting $3 p$ losses were kindly provided by Drs J.I. Martin-Subero and R. Siebert (Institute of Human Genetics, University Hospital Schleswig-Holstein, Campus Kiel, Germany).

\section{References}

1. Hilbe W, Dirnhofer S, Greil R and Woll E: Biomarkers in nonsmall cell lung cancer prevention. Eur J Cancer Prev 13: 425-436, 2004.

2. Wiest JS, Franklin WA, Drabkin H, Gemmill R, Sidransky D and Anderson MW: Genetic markers for early detection of lung cancer and outcome measures for response to chemoprevention. J Cell Biochem Suppl 28: 2964-2973, 1997.

3. Zochbauer-Muller S, Gazdar AF and Minna JD: Molecular pathogenesis of lung cancer. Annu Rev Physiol 64681-64708, 2002.

4. Perez-Soler R, Chachoua A, Hammond LA, et al: Determinants of tumor response and survival with erlotinib in patients with non-small-cell lung cancer. J Clin Oncol 22: 3238-3247, 2004.

5. Fukuoka M, Yano S, Giaccone G, et al: Multi-institutional randomized phase II trial of gefitinib for previously treated patients with advanced non-small-cell lung cancer (The IDEAL 1 Trial) [corrected]. J Clin Oncol 21: 2237-2246, 2003.

6. Mao L, Lee JS, Kurie JM, et al: Clonal genetic alterations in the lungs of current and former smokers. J Natl Cancer Inst 89: 857-862, 1997.

7. Chung GT, Sundaresan V, Hasleton P, Rudd R, Taylor R and Rabbitts PH: Clonal evolution of lung tumors. Cancer Res 56: $1609-1614,1996$.

8. Niklinski J, Niklinska W, Chyczewski L, Becker HD and Pluygers E: Molecular genetic abnormalities in premalignant lung lesions: biological and clinical implications. Eur J Cancer Prev 10: 213-226, 2001

9. Kishimoto Y, Sugio K, Hung JY, Virmani AK, McIntire DD, Minna JD and Gazdar AF: Allele-specific loss in chromosome $9 \mathrm{p}$ loci in preneoplastic lesions accompanying non-small-cell lung cancers. J Natl Cancer Inst 87: 1224-1229, 1995.

10. Hung J, Kishimoto Y, Sugio K, Virmani A, McIntire DD, Minna JD and Gazdar AF: Allele-specific chromosome 3p deletions occur at an early stage in the pathogenesis of lung carcinoma. JAMA 273: 558-563, 1995.

11. Califano J, van der Riet $\mathrm{P}$, Westra W, et al: Genetic progression model for head and neck cancer: implications for field cancerization. Cancer Res 56: 2488-2492, 1996.

12. Smith AL, Hung J, Walker L, Rogers TE, Vuitch F, Lee E and Gazdar AF: Extensive areas of aneuploidy are present in the respiratory epithelium of lung cancer patients. Br J Cancer 73: 203-209, 1996.

13. Lu YJ, Dong XY, Guo SP, et al: 2q-, a non-random chromosomal abnormality in human non-small-cell lung cancer. Carcinogenesis 17: 1589-1593, 1996. 
14. Virmani AK, Fong KM, Kodagoda D, et al: Allelotyping demonstrates common and distinct patterns of chromosomal loss in human lung cancer types. Genes Chromosomes Cancer 21: 308-319, 1998.

15. Wistuba II, Lam S, Behrens C, et al: Molecular damage in the bronchial epithelium of current and former smokers. J Natl Cancer Inst 89: 1366-1373, 1997.

16. Sozzi G, Veronese ML, Negrini M, et al: The FHIT gene 3p14.2 is abnormal in lung cancer. Cell 85: 17-26, 1996.

17. Mitsudomi T, Oyama T, Nishida K, et al: Loss of heterozygosity at $3 p$ in non-small cell lung cancer and its prognostic implication. Clin Cancer Res 2: 1185-1189, 1996.

18. Balsara BR, Sonoda G, du Manoir S, Siegfried JM, Gabrielson E and Testa JR: Comparative genomic hybridization analysis detects frequent, often high-level, overrepresentation of DNA sequences at $3 \mathrm{q}, 5 \mathrm{p}, 7 \mathrm{p}$, and $8 \mathrm{q}$ in human non-small cell lung carcinomas. Cancer Res 57: 2116-2120, 1997.

19. Greatens TM, Niehans GA, Rubins JB, Jessurun J, Kratzke RA, Maddaus MA and Niewoehner DE: Do molecular markers predict survival in non-small-cell lung cancer? Am J Respir Crit Care Med 157: 1093-1097, 1998.

20. Schenk T, Ackermann J, Brunner C, Schenk P, Zojer N, Roka S and Drach J: Detection of chromosomal aneuploidy by interphase fluorescence in situ hybridization in bronchoscopically gained cells from lung cancer patients. Chest 111: 1691-1696, 1997.

21. Taguchi T, Zhou JY, Feder M, Litwin S, Klein-Szanto AJ and Testa JR: Detection of aneuploidy in interphase nuclei from non-small cell lung carcinomas by fluorescence in situ hybridization using chromosome-specific repetitive DNA probes. Cancer Genet Cytogenet 89: 120-125, 1996.

22. Duba HC, Hilbe W, Mehringer A, Erdel M, Thaler J and Utermann G: Hypermetaphase and interphase fluorescence in situ hybridisation for monitoring of remission status in Philadelphia chromosome positive chronic myeloid leukaemia. Int J Oncol 17: $1245-1249,2000$

23. Fiegl M, Kaufmann H, Zojer N, et al: Malignant cell detection by fluorescence in situ hybridization (FISH) in effusions from patients with carcinoma. Hum Pathol 31: 448-455, 2000.

24. Brambilla E, Travis WD, Colby TV, Corrin B and Shimosato Y: The new World Health Organization classification of lung tumours. Eur Respir J 18: 1059-1068, 2001.

25. Sobin LH and Wittekind C: TNM classification of malignant tumours. 6th edition. 2002

26. Liehr T, Uwe C and Erich G: Nucleus extraction from single mounted tissue sections. Genet Anal 15: 65-69, 1999.

27. Fiegl M, Haun M, Massoner A, et al: Combination of cytology, fluorescence in situ hybridization for aneuploidy, and reversetranscriptase polymerase chain reaction for human mammaglobin/mammaglobin B expression improves diagnosis of malignant effusions. J Clin Oncol 22: 474-483, 2004.

28. Duba HC, Erdel M, Loffler J, Wirth J, Utermann B and Utermann G: Nail patella syndrome in a cytogenetically balanced $\mathrm{t}(9 ; 17)(\mathrm{q} 34.1 ; \mathrm{q} 25)$ carrier. Eur J Hum Genet 6: 75-79, 1998.

29. Siebert R, Jacobi C, Matthiesen P, et al: Detection of deletions in the short arm of chromosome 3 in uncultured renal cell carcinomas by interphase cytogenetics. J Urol 160: 534-539, 1998.

30. Sekido Y, Fong KM and Minna JD: Progress in understanding the molecular pathogenesis of human lung cancer. Biochim Biophys Acta 1378: F21-F59, 1998.

31. Braithwaite KL and Rabbitts PH: Multi-step evolution of lung cancer. Semin Cancer Biol 9: 255-265, 1999.

32. Sundaresan V, Ganly P, Hasleton P, Rudd R, Sinha G, Bleehen NM and Rabbitts P: p53 and chromosome 3 abnormalities, characteristic of malignant lung tumours, are detectable in preinvasive lesions of the bronchus. Oncogene 7: 1989-1997, 1992

33. Fong KM, Sekido Y, Gazdar AF and Minna JD: Lung cancer 9: Molecular biology of lung cancer: clinical implications. Thorax 58: 892-900, 2003.

34. Thiberville L, Payne P, Vielkinds J, et al: Evidence of cumulative gene losses with progression of premalignant epithelial lesions to carcinoma of the bronchus. Cancer Res 55: 5133-5139, 1995.

35. Sozzi G, Pastorino U, Moiraghi L, et al: Loss of FHIT function in lung cancer and preinvasive bronchial lesions. Cancer Res 58: 5032-5037, 1998 .
36. Fong KM, Biesterveld EJ, Virmani A, et al: FHIT and FRA3B 3 p14.2 allele loss are common in lung cancer and preneoplastic bronchial lesions and are associated with cancer-related FHIT cDNA splicing aberrations. Cancer Res 57: 2256-2267, 1997.

37. Kishimoto Y, Murakami Y, Shiraishi M, Hayashi K and Sekiya T: Aberrations of the p53 tumor suppressor gene in human non-small cell carcinomas of the lung. Cancer Res 52: 4799-4804, 1992.

38. Brambilla E, Gazzeri S, Lantuejoul S, Coll JL, Moro D, Negoescu A and Brambilla C: p53 mutant immunophenotype and deregulation of p53 transcription pathway $(\mathrm{Bcl} 2, \mathrm{Bax}$, and Waf1) in precursor bronchial lesions of lung cancer. Clin Cancer Res 4: 1609-1618, 1998.

39. Takahashi T, Nau MM, Chiba I, et al: p53: a frequent target for genetic abnormalities in lung cancer. Science 246: 491-494, 1989

40. Lemon SJ, Sabichi AL and Birrer MJ: Genetic alterations in lung cancer. Cellular Cancer Markers. Humana Press Inc., pp209-229, 1995.

41. Vega FJ, Iniesta P, Caldes T, et al: p53 exon 5 mutations as a prognostic indicator of shortened survival in non-small-cell lung cancer. Br J Cancer 76: 44-51, 1997

42. Jassem J, Jassem E, Jakobkiewicz-Banecka J, et al: P53 and $\mathrm{K}$-ras mutations are frequent events in microscopically negative surgical margins from patients with nonsmall cell lung carcinoma. Cancer 100: 1951-1960, 2004.

43. Sherr CJ: Cancer cell cycles. Science 274: 1672-1677, 1996.

44. Ewen ME: The cell cycle and the retinoblastoma protein family. Cancer Metastasis Rev 13: 45-66, 1994.

45. Geradts J, Fong KM, Zimmerman PV, Maynard R and Minna JD Correlation of abnormal RB, p16ink4a, and p53 expression with $3 p$ loss of heterozygosity, other genetic abnormalities, and clinical features in 103 primary non-small cell lung cancers. Clin Cancer Res 5: 791-800,1999.

46. Reissmann PT, Koga H, Takahashi R, et al: Inactivation of the retinoblastoma susceptibility gene in non-small-cell lung cancer. The Lung Cancer Study Group. Oncogene 8: 19131919, 1993.

47. Cagle PT, El Naggar AK, Xu HJ, Hu SX and Benedict WF: Differential retinoblastoma protein expression in neuroendocrine tumors of the lung. Potential diagnostic implications. Am J Pathol 150: 393-400, 1997

48. Dosaka-Akita H, Hu SX, Fujino M, et al: Altered retinoblastoma protein expression in nonsmall cell lung cancer: its synergistic effects with altered ras and p53 protein status on prognosis. Cancer 79: 1329-1337, 1997.

49. Liggett WH Jr and Sidransky D: Role of the p16 tumor suppressor gene in cancer. J Clin Oncol 16: 1197-1206, 1998.

50. Xiao S, Li D, Corson JM, Vijg J and Fletcher JA: Co-deletion of p15 and p16 genes in primary non-small cell lung carcinoma. Cancer Res 55: 2968-2971, 1995.

51. Gorgoulis VG, Zacharatos P, Kotsinas A, et al: Alterations of the p16-pRb pathway and the chromosome locus 9p21-22 in non-small-cell lung carcinomas: relationship with p53 and MDM2 protein expression. Am J Pathol 153: 1749-1765, 1998.

52. Okami K, Cairns P, Westra WH, et al: Detailed deletion mapping at chromosome 9p21 in non-small cell lung cancer by microsatellite analysis and fluorescence in situ hybridization. Int J Cancer 74: 588-592, 1997.

53. Sanz-Ortega J, Saez MC, Sierra E, et al: 3p21, 5q21, and 9p21 allelic deletions are frequently found in normal bronchial cells adjacent to non-small-cell lung cancer, while unusual in patients with no evidence of malignancy. J Pathol 195: 429-434, 2001

54. Doubre H, Cesari D, Mairovitz A, et al: Multidrug resistanceassociated protein (MRP1) is overexpressed in DNA aneuploid carcinomatous cells in non-small cell lung cancer (NSCLC). Int J Cancer 113: 568-574, 2005.

55. Wong MP, Fung LF, Wang E, et al: Chromosomal aberrations of primary lung adenocarcinomas in nonsmokers. Cancer 97 $1263-1270,2003$.

56. Sato M, Mori Y, Sakurada A, Fujimura S and Horii A: The $\mathrm{H}$-cadherin (CDH13) gene is inactivated in human lung cancer. Hum Genet 103: 96-101, 1998.

57. Kuramochi M, Fukuhara H, Nobukuni T, et al: TSLC1 is a tumor-suppressor gene in human non-small-cell lung cancer. Nat Genet 27: 427-430, 2001

58. Murakami Y: Functional cloning of a tumor suppressor gene, TSLC1, in human non-small cell lung cancer. Oncogene 21 : 6936-6948, 2002 
59. Dai Z, Zhu WG, Morrison CD, et al: A comprehensive search for DNA amplification in lung cancer identifies inhibitors of apoptosis cIAP1 and cIAP2 as candidate oncogenes. Hum Mol Genet 12: 791-801, 2003.

60. Romeo MS, Sokolova IA, Morrison LE, et al: Chromosomal abnormalities in non-small cell lung carcinomas and in bronchial epithelia of high-risk smokers detected by multi-target interphase fluorescence in situ hybridization. J Mol Diagn 5: 103-112, 2003.

61. Kurie JM, Shin HJ, Lee JS, et al: Increased epidermal growth factor receptor expression in metaplastic bronchial epithelium. Clin Cancer Res 2: 1787-1793, 1996.

62. Hilbe W, Dlaska M, Dirnhofer S, et al: Characterisation and predictive value of epidermal growth factor receptor status using quantitative real-time PCR combined with immunohistochemistry on non-small cell lung cancer specimens. Int $\mathbf{J}$ Oncol 23: 893-899, 2003.

63. Sokolova IA, Bubendorf L, O'Hare A, et al: A fluorescence in situ hybridization-based assay for improved detection of lung cancer cells in bronchial washing specimens. Cancer 96: 306-315, 2002.

64. Kerr KM: Pulmonary preinvasive neoplasia. J Clin Pathol 54: 257-271, 2001

65. Spira A, Beane J, Shah V, et al: Effects of cigarette smoke on the human airway epithelial cell transcriptome. Proc Natl Acad Sci USA 101: 10143-10148, 2004.

66. Baksh FK, Dacic S, Finkelstein SD, et al: Widespread molecular alterations present in stage I non-small cell lung carcinoma fail to predict tumor recurrence. Mod Pathol 16: 28-34, 2003.
67. De Juan C, Iniesta P, Vega FJ, et al: Prognostic value of genomic damage in non-small-cell lung cancer. Br J Cancer 77: 1971-1977, 1998.

68. De Anta JM, Jassem E, Rosell R, et al: TP53 mutational pattern in Spanish and Polish non-small cell lung cancer patients: null mutations are associated with poor prognosis. Oncogene 15: 2951-2958, 1997.

69. Liloglou T, Maloney P, Xinarianos G, et al: Cancer-specific genomic instability in bronchial lavage: a molecular tool for lung cancer detection. Cancer Res 61: 1624-1628, 2001.

70. Gazdar AF and Minna JD: Molecular detection of early lung cancer. J Natl Cancer Inst 91: 299-301, 1999.

71. Mulshire JL, Linnoila RI, Jensen SM, et al: Rational targets for early detection of lung cancer. Natl Cancer Inst Monogr: 13183-13190, 1992

72. Fong KM, Sekido Y and Minna JD: Molecular pathogenesis of lung cancer. J Thorac Cardiovasc Surg 118: 1136-1152, 1999.

73. Ahrendt SA, Chow JT, Xu LH, et al: Molecular detection of tumor cells in bronchoalveolar lavage fluid from patients with early stage lung cancer. J Natl Cancer Inst 91: 332-339, 1999.

74. Li C, Chen Z, Xiao Z, et al: Comparative proteomics analysis of human lung squamous carcinoma. Biochem Biophys Res Commun 309: 253-260, 2003.

75. Diederich S and Wormanns D: Impact of low-dose CT on lung cancer screening. Lung Cancer 45: S13-S19, 2004. 